\title{
Unique Ikaite columns under pressure by warming seawater
}

\author{
GABRIELLE JARVIK STOCKMANN ${ }^{1}$, PAUL G. \\ SEAMAN $^{2}$, ERIK STURKELL ${ }^{3}$, RICHARD \\ GYLLENCREUTZ ${ }^{4}$, SIGRÍĐUR MARÍA \\ AĐALSTEINSDÓTTIR ${ }^{1}$ AND TONCI BALIC-ZUNIC ${ }^{5}$
}

${ }^{1}$ University of Iceland

${ }^{2}$ Independent researcher

${ }^{3}$ University of Gothenburg

${ }^{4}$ Stockholm University

${ }^{5}$ University of Copenhagen

Presenting Author: gabrielle@hi.is

Over the past 25 years, numerous biological, geological and geophysical studies have been carried out in Ikka Fjord in SW Greenland describing its unique ikaite $\left(\mathrm{CaCO}_{3} \cdot 6 \mathrm{H}_{2} \mathrm{O}\right)$ columns and the remarkable microbiological ecosystem they host inside. In 1995-97, effort was put into mapping the columns and making a thorough geochemical description of how these columns form in Ikka Fjord. This is the only place on Earth they occur. In 2018-19, a new mapping campaign of the columns was carried out by use of drone imaging and multi-beam sonar surveys. In addition, seawater temperature was measured around selected columns at different depths combined with sampling of column pieces at the same spots as the temperature measurements. The column samples were analysed by X-ray diffraction (XRD) to check for possible mineral alteration. The overall goal was to record any changes to the columns that may have occurred over the past 25 years in response to warming seawater.

Our data shows that the seawater temperature around the columns has risen above the $6^{\circ} \mathrm{C}$ threshold judged necessary for a long-term stability of the ikaite mineral. In June 2019, the temperature of the water column ranged from $6-10^{\circ} \mathrm{C}$ compared to $0-6^{\circ} \mathrm{C}$ in the summers of $1995-97$. The mineralogy of the columns have changed, from almost pure ikaite in the nineties to now apartly altered into less hydrated $\mathrm{CaCO}_{3}$ minerals, which we interpret as a response to seawater warming. The previous mapping campaign detected 678 individual columns above 1 metre's height, whereas the new survey identified 938 individual columns of 0.5-20 meters height. Thus, we conclude that the hydrological-geochemical system controlling new growth of columns is still functioning, but the long-term stability of the columns and thereby their microbial ecosystem is threatened by the warming seawater. 